\title{
Tekirdağ Kıyı Bölgesinden Toplanan Balıklarda Kalıcı Organik Kirleticiler (KOK)
}

\author{
Ayşe Handan DÖKMECi ${ }^{*}$, Temine ŞABUDAK², Aslı şiMŞEK ÖZBEK \\ ${ }^{1}$ Tekirdağ Namık Kemal Üniversitesi, Sağlık Yüksekokulu, Acil Yardım ve Afet Yönetimi Bölümü, Tekirdağ. \\ ${ }^{2}$ Tekirdağ Namık Kemal Üniversitesi, Fen Edebiyat Fakültesi, Kimya Bölümü, Tekirdağ. \\ ${ }^{3}$ Tekirdağ Namık Kemal Üniversitesi, Fen Bilimleri Enstitüsü, Tekirdă̆.
}

\begin{abstract}
*Sorumlu yazar e-posta: *hdokmeci@nku.edu.tr ORCiD ID: http://orcid.org/0000-0002-4439-4422 tsabudak@nku.edu.tr ORCIDID: http://orcid.org/0000-0003-4384-4265 aslisimsek@gmail.com ORCiD ID: http://orcid.org/0000-0001-5080-7812
\end{abstract}

Geliş Tarihi: 21.05.2019; Kabul Tarihi: 01.11.2019

Öz

Bu çalışmada, Tekirdağ kıyı bölgesinden toplanan balıklarda, Kalıcı Organik Kirletici (KOK) olan Organoklorlu Pestisit (OCP) ve Polisiklik Aromatik Hidrokarbonların (PAH) kalıntıları tayin edilmiştir. Yapılan literatür araştırması sonucunda, Tekirdağ kıyı bölgesinde balıklarda OCP ve PAH kalıntıları

Anahtar kelimeler Balık; Organoklorlu pestisit; Polisiklik aromatik hidrokarbon; Tekirdağ. tayiniyle ilgili bir çalışmaya rastlanmamıştır. Bu bağlamda, sunulan çalışma ilk defa literatüre sunulmuş olan, özgün bir çalışma niteliğindedir. Tekirdağ kıyı şeridinde belirlenen 4 farklı istasyondan 2018 yılı bahar mevsiminde 4 farklı tür dip balığı; mezgit balığı, dil balığı, tekir balığı, fener balı̆̆ örnekleri toplanmıştır. Toplanan her bir balık numunesi, Hekzan: Aseton (1:1) çözeltisiyle, Soxhlet ekstraksiyonuna tabi tutulmuş ve ardından organik faz kromatografik yöntemle saflaştırılmıştır. Saflaştııılan numunelerde, OCP ve PAH kalıntı analizleri, GC-EDC ve GC-MS cihazları kullanılarak gerçekleştirilmiştir. Elde edilen sonuçlara göre, 4 farklı balık türünde tespit edilen OCP ve PAH kalıntı miktarları, FAO/WHO ve Türk Gıda Kodeksi (TGK) Maksimum Kalıntı Limit (MRL) değerleriyle karşılaştırılmış ve bulunan değerleri MRL değerlerinin altında çıktığı tespit edilmiştir.

\section{Permanent Organic Pollutants in Fish Collected from Tekirdag Coastal Region (POPs)}

\footnotetext{
Keywords

Fish;

Organochlorinated pesticide; Polycyclic aromatic hydrocarbon; Tekirdağ
}

\begin{abstract}
In this study, residues of Organochlorine Pesticide (OCP) and Polycyclic Aromatic Hydrocarbons (PAH) which are Permanent Organic Pollutants (POPs) were determined in fish collected from Tekirdağ coastal region. As a result of the literature research, no study was found on the determination of OCP and PAH residues in fish in the coastal region of Tekirdağ. In this context, the present study is an original study presented to the literature for the first time. In order to investigate the presence of OCP and PAH residue in Marmara Sea fish species, samples of 4 different bottom fish (sole, whiting, striped red mullet and angler fish) were collected from 4 different stations in the coastal line of Tekirdağ province in the spring of 2018. Each collected fish sample was subjected to Soxhlet extraction with Hexane: Acetone (1: 1) solution and then the organic phase was purified by chromatography. In purified samples, OCP and PAH residue analyzes were performed using GC-EDC and GC-MS devices. According to the results obtained, the OCP and PAH residual amounts determined in 4 different fish species were compared with FAO / WHO and Turkish Food Codex (TGK) Maximum Residual Limit (MRL) values and the values found to be below the MRL values.
\end{abstract}




\section{Giriş}

Dünyada 3 milyon tona, ülkemizde ise 30 bin tona ulaşan pestisit tüketimi söz konusudur (Delen 2008). Pestisitlerin hatalı kullanımına ya da aşırı kullanımına bağlı olarak gerek çevre ile ilgili gerekse sağlıkla ilgili önemli sonuçlar ortaya çıkmıştır. Yaygın kullanım, havadan ilaçlamalar evcil hayvanların ve kuşların büyük oranda ölmesine neden olurken hatalı kullanımlar, aşırı kullanımlar su kaynaklarının kirlenmesine, doğal çevrenin de yok edilmesine yol açmıştır. Bu kirleticiler beslenme zincirinde, yukarıya doğru birikmekte ve yaban hayatı üzerinde çeşitli etkilere yol açmaktadırlar. Özellikle klorlu insektisitler olmak üzere, birçok insektisitin hayvan etlerinde, yağ dokusunda ve diğer gıda maddelerinde bulunması mümkün hale gelerek, sağlık için önemli tehlikeler oluşturmaktadır (Mazet ve ark. 2005).

Organoklorlu pestisitler aşırı dozda kullanıldıkça, daha çok kronik zehirlenmelere neden olmakta, sinir sistemini etkilemekte ve karaciğere zarar vermektedirler (Tiryaki et al. 2010). Pestisitlerin ve türevlerinin bitki ve hayvan bünyelerinde depolanarak besin zincirine katılmaları son yılların en büyük sorunları arasında yer almaktadır. Pestisitlerin çevrede uzun süre kalmaları, biyolojik birikme eğilimleri ve hedef olmayan türlere olan etkileri sağlık ve ekosistem açısından büyük tehlike oluşturmaktadır. Bu yüzden pestisitlerin gıda, su ve çevrede izlenmeleri; sağlığın korunması, çevresel değerlendirme ve kirlilik kontrolü için gereklidir (Erdem 2010).

Polisiklik aromatik hidrokarbonlar (PAH) da çevremizde her yerde görülen yaygın organik kirleticilerdir (Kong et al. 2005). Polisiklik aromatik hidrokarbonlar, iki ya da daha fazla benzen halkasına sahip hidrofobik karakterli organik bileşiklerdir (Zhang et al. 2006, Wang et al. 2010). PAH'ların, hidrofobik yapılarından dolayı sudaki çözünürlükleri oldukça azdır. Ancak yüksek oranda lipofilik özelliğe sahiptirler. Polisiklik aromatik hidrokarbonlar organik bileşiklerin eksik yanması sonucu, egzoz gazları, organik maddelerin diagenetik prosesleri, orman yangınları ve mikrobiyolojik sentezler yada dönüşümler sonucu ortaya çıkan toksik ve kansorejen etkiye sahip organik yapıda bileşiklerdir. Polisiklik hidrokarbonlar hem gıdalarda birikirler hem de çevresel kirleticiler olarak atmosferde doğrudan bulunurlar. Bu yüzden hava, toprak ya da sular da bu maddeler tarafından etkilenmektedir (Lopez 2003). Bu sebeple PAH'ların varlığı, insan sağıı̆ı açısından oldukça önemlidir. PAH'ların molekül ağırlıkları arttıkça sudaki çözünürlükleri azalmaktadır. Ancak toksik ve kanserojenik özellikleri artmaktadır (Wenzl et al. 2006, Ferrarese et al. 2008). Her yıl yaklaşık 43000 ton $\mathrm{PAH}$ atmosfere ve 230000 ton PAH su ortamına verilmektedir (Eisler 2000).

Tekirdağ, Türkiye'de iki denize de (Marmara denizi ve Karadeniz) kıyısı olan altı ilden biridir. Marmara Denizinin bütün etkenleri ile iç içe bulunmakta ve il üzerindeki her türlü olumlu ve olumsuz etkilerine maruz kalmaktadır (Int Kyn. 1). Marmara Denizi 1960 'lı yıllardan beri hem endüstriyel hem de evsel atıklarla kirlenmiştir. Ayrıca bölgedeki tarımsal faaliyetler, gemi atık suları ve atmosferik çökelme nedeniyle oluşan kirlilikten (Int Kyn. 2).Tekirdağ ili genelinde bugün 1180 adet sanayi kuruluşu mevcuttur. Havza boyunca yer altı suyu tüketimine dayalı tekstil, deri, kağıt ve kimya sektörlerine ait tesislerin artması ile birlikte yüzeysel sularımızda kalite bozulmaya başlamıştır. 2017 yılında, Tekirdağ ili genelinde tarımsal faaliyetlerde 635.300 ton pestisit kullanıldığı Tekirdağ ill Gıda, Tarım ve Hayvancılık Müdürlüğü tarafından bildirilmiştir (Çizelge 1) (Int Kyn. 3).

Çizelge 1. Tekirdağ ilinde 2017 yılında tarımda kullanılan pestisitlerin miktarı

\begin{tabular}{|c|c|c|}
\hline $\begin{array}{l}\text { Kimyasal } \\
\text { Maddenin Adı }\end{array}$ & $\begin{array}{l}\text { Kullanım } \\
\text { Miktarı (ton) }\end{array}$ & $\begin{array}{l}\text { Tarım İlacı } \\
\text { Kullanılarak } \\
\text { Tarım } \\
\text { Yapılan Alan } \\
\text { (ha) }\end{array}$ \\
\hline İnsekdisitler & 48.439 & \\
\hline Herbisitler & 296.832 & \\
\hline \multirow[t]{2}{*}{ Fungisitler } & 285.053 & \\
\hline & & $415.760,6$ \\
\hline Rodentisitler & 0.875 & \\
\hline Akarisitler & 2.662 & \\
\hline $\begin{array}{l}\text { Diğer } \\
\text { (Nematodlar, } \\
\text { Kabuklu Bitler } \\
\text { vb.) }\end{array}$ & 1.439 & \\
\hline Toplam & 635.300 & $415.760,6$ \\
\hline
\end{tabular}


Türkiye genelinde, toplam deniz ürünlerinin \%11.7'sini Marmara Denizi'nin karşılaması nedeniyle, Tekirdağ ili balıkçılık açısından önemli bir potansiyele sahip bulunmaktadır (Abdikoğlu ve Aygün 2015). Bu çalışmadaki amacımız, Tekirdağ kıyı şeridindeki 4 farklı istasyondan (Şarköy, Tekirdağ Merkez, Yenice, Marmara Ereğlisi) toplanan, 4 farklı tür dip balıklarında (mezgit, dil, tekir ve fener), kalıcı organik kirleticilerin (OCP ve PAH) miktarlarını tayin etmektir. Çalışma sonucunda, Tekirdağ bölgesindeki tüketilen balık türlerindeki OCP ve $\mathrm{PAH}^{\prime}$ ların insan ve çevre sağlığı açısından sınır değerlerin üzerinde olup olmadığı araştırılmış ve çevre sorunlarının çözümüne katkı sağlanmış olacaktır.

\section{Materyal ve Metot}

\subsection{Balık numunelerinin toplanması}

Tekirdağ kıyı şeridinde belirlenen 4 farklı istasyondan (Şarköy, Tekirdağ, Yenice, Marmara Ereğlisi), 2018 yılı bahar mevsiminde 4 farklı tür dip balığı, dil balığı, mezgit balığı, tekir balığı, fener balığı örnekleri toplanarak; organik klorlu pestisit (OCP) ve polisiklik aromatik hidrokarbonların (PAH) kalıntı miktarları GC-MS cihazı kullanılarak tespit edilmiştir. Balık örneklerinin toplandığı bu istasyonlar, özellikle, Tekirdağ kıyı şeridini, kuzeyden güneye doğru temsil ettiği için seçilmiştir. Deniz tabanının (sediment) yakınında yaşayan bu balık türleri, Kalıcı Organik Kirleticileri bünyelerinde daha fazla akümüle edebileceğinden dolayı bu balık türleri tercih edilmişlerdir. Bu çalışmada farklı derinliklerden dip balıklarını avlamak için algarna yöntemi ve dip ağı yöntemi kullanılmıştır. 4 farklı noktadan toplanan balık örnekleri buz kutusunda laboratuvara getirilmiştir. Tüm örneklerin alındığı noktalar Global Position System (GPS) kullanılarak belirlenmiştir. Tam olarak her örneğin koordinatı ve örneklerin alındığı derinlikler Çizelge 2 ve Şekil 1' de gösterilmiştir.

Çizelge 2. Numunelerin alındığı istasyonların lokasyonları ve derinlikleri

\begin{tabular}{|c|c|c|}
\hline Bölge & Koordinat & Derinlik (m) \\
\hline ŞRK & $\begin{array}{c}40.664112,27.247966 \\
40^{\circ} 39^{\prime} 50.8^{\prime \prime N} 27^{\circ} 14^{\prime} 52.7^{\prime E}\end{array}$ & 11 \\
\hline
\end{tabular}

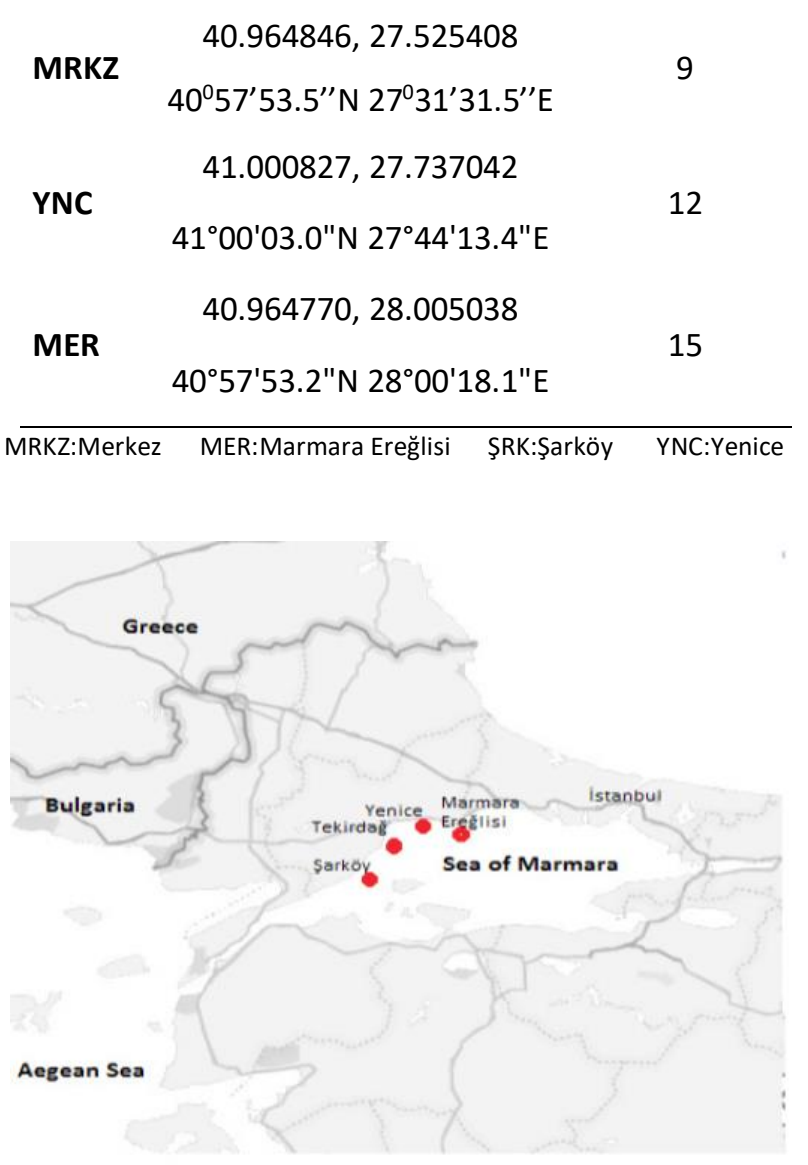

Şekil 1. Balık numunelerinin toplandığı istasyonlar

Balık numunelerinin kas dokusunu ayırmadan önce her biri distile su ile yıkandıktan sonra boy ve uzunlukları ölçülüp polietilen poşetlere konulmuş ve analize kadar $-30 \%$ de muhafaza edilmişlerdir (Çizelge 3).

Çizelge 3. Dört farklı istasyondan toplanan balıkların ortalama boy ve ağırlıkları

\begin{tabular}{clcccc}
\hline $\begin{array}{c}\text { Balık } \\
\text { Türü }\end{array}$ & $\begin{array}{l}\text { Boy(cm)/ } \\
\text { Ağırık(g) }\end{array}$ & ŞRK & MRKZ & MER & YNC \\
\hline $\begin{array}{l}\text { Tekir } \\
\text { Balığı }\end{array}$ & Ort. Boy & 14.5 & 15.2 & 11.7 & 11.4 \\
& $\begin{array}{l}\text { Ort. } \\
\text { Ağılık }\end{array}$ & 32.2 & 52.9 & 16.9 & 16.2 \\
$\begin{array}{l}\text { Fener } \\
\text { Balığı }\end{array}$ & Ort. Boy & 53 & 65 & 52 & 57.7 \\
& $\begin{array}{l}\text { Ort. } \\
\text { Ağırlık }\end{array}$ & 3262 & 5016 & 3187 & 3875 \\
Dil & $\begin{array}{l}\text { Ort. Boy } \\
\text { Balığı }\end{array}$ & 23.7 & 21.5 & 21.7 & 23.9 \\
& $\begin{array}{l}\text { Ort. } \\
\text { Ağırlık }\end{array}$ & 113 & 74 & 85.6 & 122 \\
Mezgit & Ort. Boy & 26.3 & 27.2 & 29.2 & 30.2 \\
& $\begin{array}{l}\text { Ort. } \\
\text { Ağırlık }\end{array}$ & 172.4 & 183.8 & 183.5 & 261 \\
\hline & & & & & \\
\hline
\end{tabular}




\subsection{Balık numunelerinde OCP ve $P A H$ analizi}

Dondurulmuş balık numuneleri oda sıcaklığında çözdürüldükten sonra, her bir balığın kas örnekleri ayrılmış ve analiz için her numune $600 C^{\prime}$ de 24 saat etüvde kurutulmuştur. Kas dokusunu ayırırken herhangi bir bulaşmayı önlemek için plastik bıçak kullanılmıştır. Balıklarda OCP ve PAH analizinde ön işlem için (EPA 3540C) yaklaşık $10 \mathrm{~g}$ numune tartılıp, soxhlet kartuşlarına alınmıştır. Üzerine numunede bulunan suyu tutmasını sağlamak amacıyla sodyum sülfat eklenmiştir. Numuneler $150 \mathrm{~mL}$ Hekzan:Aseton (1:1) çözeltisi ile Soxhlet cihazında 3 saat ekstrakte edilmiştir. Daha sonra çözücü karışımı evaporatörde $4 \mathrm{~mL}$ kalana kadar uçurulmuş ve EPA 3630C metodunda belirtildiği gibi, karışım Silikajel kolondan, Diklorometan:Pentan (2:3) çözücü sistemi kullanarak geçirilmiş ve numuneye saflaştırma işlemi uygulanmıştır. Saflaştırma işlemi uygulanmasının ardından, OCP analizi için GC-ECD; PAH analizi için ise GC/MS kullanılarak kalıntı analizi gerçekleştirilmiştir. Analizlemede pestisitler için EPA 8081B ve EPA 8141A, PAH için EPA 8270D metodu kullanılmıştır.

\subsection{Kullanılan cihazlar}

GC-ECD (Agilent 6890N), GC-MS (Agilent 7890B), Soxhlet ekstraksiyon cihazı (Gerhart Soxterm-SE 414), Etüv (Memmert), ultra saf su cihazı (Elga DV 25 ), evaporator (Buchı Rotavapor R-210 SJ29/32).

\subsection{Kullanılan kimyasal maddeler}

Hekzan (Honeywell-34859), Aseton (Honeywell34850), Silika jel (Sigma-288624), Sodyum Sülfat (Sigma-13464), Diklorometan (Merck-106054), Pentan (Sigma-109660).

\subsection{OCP kalıntı tayininde kullanılan, GC-ECD cihazı için uygulanan kromatografik şartlar}

Marka model: Agilent marka/ 6890N, Kolon Dolgu Maddesi: DB-XLB, Dolgu Maddesi Kalınlığı: 0,25 $\mu \mathrm{m}$, Kolon boyutları: $30 \mathrm{~m}$ × $250 \mu \mathrm{m}$, Taşıyıcı Gaz:

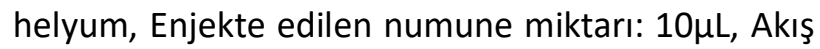
hızı: $1.5 \mathrm{~mL} / \mathrm{min}$.

2.6 PAH kalıntı tayininde kullanılan GC-MS cihazı için uygulanan kromatografik şartlar
Marka model: Agilent marka/ 7890A/ 5975C VLMSD, Kolon Dolgu Maddesi: HP-5MS 5\% fenil metil siloksan, Dolgu Maddesi Kalınlığı: 0,25 $\mu \mathrm{m}$, Kolon boyutları: $30 \mathrm{~m}$ x $250 \mu \mathrm{m}$, Taşıyıcı Ga: helyum, Enjekte edilen numune miktarı: $10 \mu \mathrm{L}$, Akış hızı: 1,5 $\mathrm{mL} / \mathrm{min}$

\section{Bulgular}

Bu çalışmada Tekirdağ kıyı bölgesinde tüketilen balık türlerindeki OCP ve PAH'ların tayini amaçlanmıştır. Çalışmamızda, analizi yapılan PAH lar; Naftalen, Asenaftelen, Floranten ve İndeno(1,2,3-c,d)piren molekülleridir. Balıklarda PAH analiz sonucu, analizi yapılan 4 maddenin toplam konsantrasyonu verilmiştir. Bu maddeler, su ortamında bulunan, kalıcı organik kirleticilerin en önemli türlerindendir. Sudaki düşük çözünürlükleri ve yüksek hidrofobik karekterleri sebebiyle, sudaki maddelere adsorplanma ve sedimentlerde birikim yapma özelliğine sahiptirler. PAH'ların sudaki taşınımı çoğunlukla su ve katı faz arasındaki tutunma ve denge mekanizmasına bağııdır. Bunun yanında, PAH'ların çevrede yayılmalarında, onların sudaki çözünürlükleri, buhar basınçları ve bileşiğin sudan lipide geçiş potansiyelleri de (logKow) etkilidir (WHO 1998, ATSDR 1995, Martinez et al. 2004). Balık numunelerinde analizi yapılan PAH ların, fiziksel özellikleri (sudaki çözünürlük, buhar basıncı, logKow) Çizelge 4 de gösterilmiştir.

Çizelge 4. Balık numunelerinde tayini yapılan PAH ların bazı fiziksel özellikleri

\begin{tabular}{lccc}
\hline PAH adı & $\begin{array}{l}\text { Sudaki } \\
\text { Çözünürlük } \\
\text { (mg/L) }\end{array}$ & $\begin{array}{l}\text { Buhar } \\
\text { Basıncı } \\
\text { (mm- } \\
\text { HG) }\end{array}$ & LogK $_{\text {ow }}$ \\
\hline Naftelen & 31 & 0.085 & 3.3 \\
Asenaftelen & 3.93 & 0.029 & 4.07 \\
Floranten & $2.0-2.6$ & $5.10^{-6}$ & 4.9 \\
Indeno(1,2,3- & 0.062 & $1.10^{-11}$ & 6.58 \\
c,d)piren & & & \\
\hline
\end{tabular}

Çalışma sonuçları değerlendirildiğinde, Tekirdağ bölgesindeki istasyonlardan toplanan 4 farklı balık türündeki OCP ve $\mathrm{PAH}$ kalıntı miktarları, WHO/FAO ve Türk Gıda Kodeksi (TGK) Maksimum Kalıntı Limit (MRL) değerleriyle karşılaştırılmış (Çizelge 5; Çizelge 
6; Çizelge 7) ve bulunan değerler, maksimum kalıntı limitlerinin altında çıkmıştır. Bu sonuç, Tekirdağ ilindeki 4 istasyondan toplanan, 4 farklı dip balığının,
Kalıcı Organik Kirleticiler açısından bir risk oluşturmadığı gibi, insan ve çevre sağı̆ğı açısından da tehdit etmediğini göstermiştir.

Çizelge 5. OCP ve PAH'lar için, WHO/FAO ve TGK tarafından kabul edilen maksimum kalıntı limitleri (MRL)

\begin{tabular}{lcc}
\hline Kalıntı Tayini Yapılan Maddeler & FAO/WHO $_{\text {MRL }}{ }^{*}(\mathbf{m g} / \mathbf{k g})$ & TGK $^{\text {MRL }}{ }^{* *}(\mathbf{m g} / \mathbf{k g})$ \\
\hline Aldrin & 0.2 & 0.2 \\
$\alpha$-Hekzaklorosiklohekzan & 0.2 & 0.2 \\
- Hekzaklorosiklohekzan & 0.2 & 0.2 \\
Y- Hekzaklorosiklohekzan & 0.2 & 0.2 \\
Dieldrin & 0.2 & 0.2 \\
Endrin & 0.1 & 0.01 \\
Lindan & 0.01 & 0.01 \\
Hegzaklorobenzen & - & 0.02 \\
4,4'-DDT & 0.3 & 0.3 \\
$\Sigma$ PAH & $0.05^{*}$ & $0.05^{*}$ \\
\hline
\end{tabular}

** Int Kyn. 4; *Int Kyn. 5 
Çizelge 6. Tekirdağ kıyı bölgesinden toplanan balıklarda PAH ve OCP kalıntı tayini sonuçları

\begin{tabular}{|c|c|c|c|c|c|c|c|c|}
\hline \multirow{2}{*}{$\begin{array}{l}\text { Balık Örneği/istasyon } \\
\text { Kalıntı Tayini Yapılan Maddeler }\end{array}$} & \multicolumn{4}{|c|}{ Tekir Balığı } & \multirow{3}{*}{$\begin{array}{c}\text { MER } \\
<0,001\end{array}$} & \multicolumn{3}{|c|}{ Mezgit Balığı } \\
\hline & MER & MRKZ & YNC & ŞRK & & MRKZ & YNC & ŞRK \\
\hline Aldrin & $<0,001$ & $<0,001$ & $<0,001$ & $<0,001$ & & $<0,001$ & $<0,001$ & $<0,001$ \\
\hline$\alpha$-Hekzaklorosiklohekzan $(\alpha-\mathrm{HCH})$ & $<0,001$ & $<0,001$ & $<0,001$ & $<0,001$ & $<0,001$ & $<0,001$ & 0,002 & 0,002 \\
\hline$\beta$ - Hekzaklorosiklohekzan ( $\beta-\mathrm{HCH})$ & 0.0003 & $<0,001$ & 0.0009 & $<0,001$ & $<0,001$ & $<0,001$ & $<0,001$ & 0.0023 \\
\hline$\delta$ - Hekzaklorosiklohekzan ( $\delta-\mathrm{HCH})$ & $<0,001$ & $<0,001$ & $<0,001$ & $<0,001$ & 0,0098 & 0.00674 & $<0,001$ & $<0,001$ \\
\hline Dieldrin & $<0,001$ & $<0,001$ & $<0,001$ & $<0,001$ & $<0,001$ & $<0,001$ & $<0,001$ & $<0,001$ \\
\hline Endrin ) & $<0,001$ & $<0,001$ & $<0,001$ & $<0,001$ & $<0,001$ & $<0,001$ & $<0,001$ & $<0,001$ \\
\hline Lindane $(\gamma-\mathrm{HCH})$ & $<0,001$ & $<0,001$ & $<0,001$ & $<0,001$ & 0,0015 & $<0,001$ & $<0,001$ & $<0,001$ \\
\hline Hegzaklorobenzen & $<0,001$ & $<0,001$ & $<0,001$ & $<0,001$ & $<0,001$ & $<0,001$ & $<0,001$ & $<0,001$ \\
\hline ¿Klorlu Pestisitler & 0,0003 & $<0,009$ & 0.0009 & $<0,009$ & 0,0114 & 0.0067 & 0,0020 & 0.0023 \\
\hline 4,4'-DDT & $<0,001$ & $<0,001$ & $<0,001$ & $<0,001$ & $<0,001$ & $<0,001$ & $<0,001$ & $<0,001$ \\
\hline$\Sigma$ PAH & $<50$ & $<50$ & $<50$ & $<50$ & $<50$ & $<50$ & $<50$ & $<50$ \\
\hline
\end{tabular}

Çizelge 7. Tekirdağ kıyı bölgesinden toplanan balıklarda PAH ve OCP kalıntı tayini sonuçları

\begin{tabular}{|c|c|c|c|c|c|c|c|c|}
\hline \multirow[t]{2}{*}{ Balık Örneği/İstasyon } & \multicolumn{4}{|c|}{ Dil Balığı } & \multicolumn{4}{|c|}{ Fener Balığı } \\
\hline & MER & MRKZ & YNC & ŞRK & MER & MRKZ & YNC & ŞRK \\
\hline \multicolumn{9}{|l|}{ Kalıntı Tayini Yapılan Maddeler } \\
\hline Aldrin & $<0,001$ & $<0,001$ & $<0,001$ & $<0,001$ & $<0,001$ & 0,00123 & 0,00014 & $<0,001$ \\
\hline$\alpha$-Hekzaklorosiklohekzan ( $\alpha-\mathrm{HCH})$ & $<0,001$ & $<0,001$ & $<0,001$ & $<0,001$ & $<0,001$ & $<0,001$ & $<0,001$ & $<0,001$ \\
\hline$\beta$ - Hekzaklorosiklohekzan ( $\beta$-HCH) & $<0,001$ & $<0,001$ & $<0,001$ & $<0,001$ & $<0,001$ & $<0,001$ & $<0,001$ & $<0,001$ \\
\hline$\delta$ - Hekzaklorosiklohekzan ( $\delta-\mathrm{HCH})$ & $<0,001$ & 0,002 & 0,0282 & 0,0006 & $<0,001$ & 0,0009 & 0,005 & 0,009 \\
\hline Dieldrin & $<0,001$ & $<0,001$ & $<0,001$ & $<0,001$ & $<0,001$ & $<0,001$ & $<0,001$ & $<0,001$ \\
\hline Endrin ) & $<0,001$ & $<0,001$ & $<0,001$ & $<0,001$ & $<0,001$ & $<0,001$ & $<0,001$ & $<0,001$ \\
\hline Lindane $(\boldsymbol{\gamma}-\mathrm{HCH})$ & $<0,001$ & $<0,001$ & $<0,001$ & $<0,001$ & $<0,001$ & 0,0001 & $<0,001$ & 0,0002 \\
\hline Hegzaklorobenzen & $<0,001$ & $<0,001$ & $<0,001$ & $<0,001$ & $<0,001$ & $<0,001$ & $<0,001$ & $<0,001$ \\
\hline 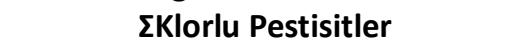 & $<0,009$ & 0,0021 & 0,0282 & 0,0007 & $<0,009$ & 0.002 & 0,005 & 0,0092 \\
\hline 4,4'-DDT & $<0,001$ & $<0,001$ & $<0,001$ & $<0,001$ & $<0,001$ & $<0,001$ & $<0,001$ & $<0,001$ \\
\hline$\Sigma$ PAH & $<50$ & $<50$ & $<50$ & $<50$ & $<50$ & $<50$ & $<50$ & $<50$ \\
\hline
\end{tabular}




\section{Tartışma ve Sonuç}

Literatürdeki benzer araştırmalar değerlendirildiğinde; 1978 yılında Erdemli'de avlanan balıklarda bulunan OCP kalıntı değerleri; toplam $\mathrm{HCH}$ miktarı $0,001-0,0018 \mathrm{mg} / \mathrm{kg}$, aldrin 0.001-0.0011 mg/kg, dieldrin $0.001 \mathrm{mg} / \mathrm{kg}, \mathrm{p}, \mathrm{p}^{\prime}-\mathrm{DDT}$ $0.0069-0.0479 \mathrm{mg} / \mathrm{kg}$ ve DDT $0.0338-0.136 \mathrm{mg} / \mathrm{kg}$ aralığında tayin edilmiştir (Balkaş 1978). Ege Denizi'nde dil balığında bulunan OCP konsantrasyonları, toplam DDT 0.002-0.0312 mg/kg olarak tespit edilmiştir (Balcı 1984). İzmir Körfezi'nde Mullus barbatus'da saptanan OCP kalıntıları, lindan <0.0001-0.037 mg/kg, heptaklor $<0.010$, aldrin 0.00081-0.0028 $\mathrm{mg} / \mathrm{kg}$, dieldrin $<0.00030-0.022 \mathrm{mg} / \mathrm{kg}$ ve $\mathrm{p}, \mathrm{p}^{\prime}-\mathrm{DDT}<0.00030 \mathrm{mg} / \mathrm{kg}$ olarak bulunmuştur (Altay 1996). Göksu Deltası'nda yapılan çalışmalarda bulunan ortalama OCP kalıntı değerleri; Aldrin $0,103 \mathrm{mg} / \mathrm{kg}$, heptaklor 0,419 $\mathrm{mg} / \mathrm{kg}, \quad p, p^{\prime}$-DDE 0,243 mg/kg bulunmuştur. Tekirdağ kıyısındaki yapılan çalışmamızda bulunan kalıntı limitleri, Ayas et al. (1997) yaptığı çalışmada bulunan kalıntı limitlerinin altında saptanmıştır. Erdoğrul et al. (2005)'nın Kahramanmaraş Sir Barajı’ı balık türlerinde yapılmış olan OCP kalıntı analizleri sonucunda, her balık türünde DDT'lerin varlığını tespit etmiştir. Hekzaklorosiklohekzan ve izomerleri ise az miktarda tespit edilmiştir. Yaptığımız bu çalışmada DDT ve Hekzaklorosiklohekzan miktarları Erdoğrul ve arkadaşlarının yapmış olduğu çalışmadan daha düşük düzeylerde tespit edilmiştir. Kalyoncu vd.(2009) 2008 yılında Konya marketlerinde satılan balıklarda OCP kalıntı tayini üzerine yaptıkları araştırmada 14 farklı OCP tayin etmişlerdir. Çalışmamızda olduğu gibi Konya bölgesindeki balıklarda da OCP kalıntı miktarı FAO/WHO ve TGK tarafindan belirlenen tolerans değerlerinin altında bulunmuştur (Çizelge 5). Erkmen ve Kolankaya (2005) Meriç Deltası'nda yaptıkları çalışmada, balık örneklerinde $\alpha$-ve $\beta-\mathrm{HCH}$ baskın hekzaklorsiklohekzan izomerleri olup 0.319$0.968 \mathrm{mg} / \mathrm{kg}$ ile $0.397-0.876 \mathrm{mg} / \mathrm{kg}$ arasında değiştiği tespit edilmiştir. p,p'-DDT'nin konsantrasyonları ise $0.0026-0.052 \mathrm{mg} / \mathrm{kg}$ arasında çıkmıştır.
Literatüre bakıldığında balık türlerinde hala pestisit kalıntılarının mevcut olmasının sebebi yarılanma ömürlerinin uzun olmasıdır. Balıklara ve doğal kaynaklara olan riski azaltmak için, OCP'lerden, suda kalıcı olmayanları tarım ilacı olarak tercih edilmeli ve uygulama metotlarına dikkat edilmesi önem arz etmektedir. Insan sağlığını ve diğer canlıların yaşam alanlarını ve çevre sağlığını tehdit ettiği için $P A H$ ve OCP kullanımlarına çok dikkat edilmelidir. Fazla ve bilinçsiz kullanılan pestisitlerin gıdada, toprakta ve suda kendisi ya da dönüşüm ürünleri kalabilmektedir. Bu nedenle kalıntıları araştırmak amacıyla sudaki canlılarda düzenli olarak kontrolleri ve analizleri sağlanmalıdır.

$\mathrm{Bu}$ çalışma, Tekirdağ kıyısında bulunan ve beslenmede insan sağlığı açısından büyük öneme sahip olan balıkların OCP ve PAH kalıntı miktarlarının ortaya konularak, bulunan değerlerin risk oluşturacak düzeyde çıkmaması açısından dikkate değer bir çalışma olarak görülmektedir.

\section{Teşekkür}

Bu çalışmanın finansal desteği, Namık Kemal Üniversitesi Bilimsel Araştırma Projeleri Birimi (NKUBAP.23.GA.18.158) tarafından sağlanmıştır. NKUBAP birimine, vermiş olduğu destekten dolayı teşekkür ederiz.

\section{Kaynaklar}

ATSDR, Agency for Toxic Substances and Disease Registry (ATSDR). (1995). Toxicological profile for polycyclic aromatic hydrocarbons (PAHs). Atlanta (GA): Department of Health and Human Services, Public Health Service, USA.

Abdikoğlu, D.İ., Azabağaoğlu M.Ö., Unakıtan, G., 2015. Tekirdağ ilinde Balık Tüketim Eğilimlerinin Belirlenmesi. Balkan and Near Eastern Journal of Social Sciences Balkan ve Yakın Doğu Sosyal Bilimler Dergisi, 69, 143-145.

Altay, O., 1996. İzmir Körfezinde Pestisit Kirliliğinin Araştırılması. DEÜ. Fen Bilimleri Enstitüsü Doktora Tezi. İzmir,75.

Ayas, Z., Barlas, N.E., Kolankaya, D., 1997. Determination of organochlorine pesticide residues in various environments and organisms in Göksu Delta, Turkey. Aquatic Toxicology 39: 171-181. 
Balcı, A., 1984. Ege Denizi Kıyılarında Klorlu Pestisitlerin Dağılımı. DAÜ Fen Bilimleri Enstitüsü, Yüksek Lisans Tezi, İzmir, 110.

Balkaş, I.T., 1978. Trace Metals and Organochlorine Residue Contect of Mullidae Family Fishes and Sediment in Vicinity of Erdemli. I. Journees Etud Pollution. CIESM, 159-163.

Delen, N., 2008. Fungisitler. 1360, Nobel Yayın Dağıtım Tic. Ltd. Şti., Ankara. 318s.

Eisler, R., 2000. Handbook of Chemical Risk Assessment Health Hazards to Humans Plants and Animals, Chapter 25.Lewis Publisher, Washington D.C.

Erdem., Ö., 2010. Ankara Ayaş ilçesindeki içme ve sulama sularında organoklorlu pestisitlerin kromatografik tayini. Gazi Üniversitesi Fen Bilimleri Enstitüsü, Yüksek Lisans Tezi, Ankara, 78.

Erdoğrul, O., Covacı, A., Schepens, P., 2005. Levels of Organochlorine Pesticides, Polychlorinated Biphenyls and Polybrominated Diphenyl Ethers in Fish Species From Kahramanmaraş, Turkey. Environment International, 31:703-711.

Erkmen, B ve Kolankaya D., 2006. Determination of organochlorine pesticide residues in water, sediment and fish samples from the Meriç Delta, Turkey. Int. J. Environ. Anal. Chem, 86: 161- 169.

Ferrarese, E., Andreottola, G., Oprea, I.A.,2008. Remediation of PAH contaminated sediments by chemical oxidation. Journal of Hazardous Materials, 152, 1: 28-39.

Haktanır, K., ve Arcak, S., 1998. A.Ü.Z.F. Çevre Kirliliği Ders Kitabı, 1503:457.

Kalyoncu, L., Ağca, İ., Aktümsek, A., 2009. Some organochlorine pesticide residues in fish species in Konya, Turkey. Chemosphere, 74: 885-889.

Kong, K.Y., Cheung, K.C., Wong, C.K.C and Wong, M.H., 2005. The Residual Dynamics of Polycyclic Aromatic Hydrocarbons and Organochlorine Pesticides in Fishponds of the Pearl River Delta, South China. Water Research, 39: 1831-1843.

Koren, H., Bisesi. M., 1996. Handbook of Environmental Health and Safety, CRC. Inc, USA, 275-310.

Lopez-Barea, J., Rodriguez-Ariza, Rodriguez-Ortega, M.J., Marenco, J.L., Amezcua, O., Alhama, J.,2003. Uptake and Clearance of PCB Congeners in Chamaelea Gallina: Response of Oxidative Stress Biomarkers.Comparative Biochemistry and Physiology Part C:Toxicology Pharmacology, 134(1): 57-67.

Martinez, E., Gros, M., Lacorte, S., Barcelo, D., 2004. Simplified procedures for the analysis of polycyclic aromatic hydrocarbons in water, sediments and mussels. Journal of Chromatography A, 1047, 181188.

Morgan, D.B .,1992. Pesticides, Chemicals and Health, The BMA Guide, British Medicai Association, Echvard Arnold, A Division of Hodder, Sotughton, London.

Tiryaki, O., Canhilal, R., Horuz, S., 2010. Tarım İlaçları Kullanımı ve Riskleri. Erciyes Üniversitesi Fen Bilimleri Enstitüsü Dergisi, 26: 154-169.

US Environmental Protection Agency (US EPA) 1996. Method 3630, Revision B. Silica Gel Cleanup. SW-846 Manual. Washington, DC, USA.

US Environmental Protection Agency (US EPA) 2014. Method 8270D: Semivolatile organic compounds by gas chromatography/mass spectroscopy, part of Test Methods for Evaluating Solid waste, Physical/Chemical Methods. Washinghton,EPA Publication SW-846.

US Environmental Protection Agency (US EPA) 1998a. Draft Update IVA. January 1998. Method 8141B. Organophosphorus Compounds by Gas Chromatography. United States Environmental Protection Agency, Washington DC.

US Environmental Protection Agency (US EPA) 1998b. Draft Update IVB. January 1998. Method 8081B. Organochlorine Pesticides by Gas Chromatography. United States Environmental Protection Agency, Washington DC. Available at:

Wang, X.Y., Li, Q.B., Luo, Y.M., Ding, Q, Xi, L.M., Ma, J.M., Li, Y., Liu, Y.P., Cheng, C.L., 2010. Characteristics and sources of atmospheric polycyclic aromatic hydrocarbons (PAHs) in Shanghai, China. Environmental Monitoring and Assessment, 165: 295305

Wenzl, T., Simon, R., Anklam, E., Kleiner, J., 2006. Analytical methods for polycyclic aromatic hydrocarbons (PAHs) in food and the environment needed for new food legislation in the European Union. Trends in Analytical Chemistry, 25: 716- 725. 
WHO, World Health Organisation (1998). Environmental Health Criteria 202, Selected non-heterocyclic polycyclic aromatic hydrocarbons. IPCS, International Programme on Chemical Safety. World Health Organisation, Geneva.

Zhang, J.L.G., Li, X.D., Qi, S.H., Liu, G.Q., Peng, X.Z., 2006. Source seasonality of polycyclic aromatic hydrocarbons (PAHs) in subtropical city, Guangzhou, South China. Science of the. Total Environment, 355: 145-155.

\section{internet kaynakları}

1.https://webdosya.csb.gov.tr/db/ced/editordosya/TEKI RDAG\%20IL\%20CEVRE\%20DURUM\%20RAPORU\%20201

6-NIHAI.pdf, (02.04.2018)

2.http://marmara.gov.tr/UserFiles/Attachments/2018/1 2/28/5b310972-a243-4ad4-b777-d64bf43365a0.pdf, (16.12.2018)

3.https://webdosya.csb.gov.tr/db/ced/icerikler/tekrdag_-cdr2017-20181114160234.pdf, (09.10.2019)

4.http://www.resmigazete.gov.tr/eskiler/2016/11/2016 1125M1-1.htm. EK-3 Bölüm- 2B. (29.08.2018) 5.http://www.fao.org/faowhocodexalimentarius/standa rds/pestres/commodities detail/en/?lang=en\&c_id=158, (12.06.2018) 